\title{
ROYALTIES FOR ARTISTS VERSUS ROYALTIES FOR AUTHORS AND COMPOSERS
}

\author{
Henry Hansmann \\ Yale Law School \\ Marina Santilli \\ New York City
}

January 2001

This paper was given at the panel on "The Moral, Legal, and Economic Rights of Artists" at the $11^{\text {th }}$ Annual ACEI Conference, Minneapolis, May 2000. It had its origins in a presentation to the Comparative Law and Economics Forum in Brussels. For helpful comments and discussions we are grateful to participants in those meetings, to lan Ayres, Michael Klausner, William Landes, Dean Leuck, Roberta Romano, and Ruth Towse, to participants in workshops at the University of Chicago, New York University, and Yale, and to participants in the Fifth Symposium on Law and Economics at Travemunde, Germany.

Printed: April 11, 2001 


\begin{abstract}
Legislation creating or reinforcing resale royalties for visual artists retains substantial political popularity, particularly in the European Union -- despite the often skeptical attitude toward those rights in the economics literature. In this essay, we probe more deeply the affirmative arguments that can be made for a resale royalty right, in either a mandatory or a discretionary form. We also compare the rationale for visual artists' resale royalties with the potential rationales for the now-well-established systems of royalty rights for authors and composers. This comparison has particular interest both because some of the principal arguments made against visual artists' resale royalties also apply to authors' royalties, and because the economic rationale for compensating authors with royalties has itself not been well explored. We also discuss briefly the related subject of display rights for visual artists. We conclude with some general implications for policy.
\end{abstract}




\section{INTRODUCTION}

A number of European nations have, by law, conferred on visual artists such as painters and sculptors a royalty right in all future resales of their work. This royalty right typically consists of a claim to a given fraction of either the gross or net proceeds received for a work by the artist when the current owner of the work resells it.

The precise form of the right differs from one jurisdiction to another. ${ }^{1}$ For example, under French law, from which the right derives the commonly-used name "droit de suite," the artist is entitled to $3 \%$ of the gross sales price from any subsequent sale of his work, by public auction or through a dealer, where the price exceeds 100 francs. Under Italian law, in contrast, an artist is entitled to collect between $2 \%$ and $10 \%$ of the amount by which any subsequent sale price of his work, in a public sale, exceeds the work's first sale price, the precise percentage being determined by a complicated schedule that depends on the sale price and the type of work involved. At the same time, some European civil law jurisdictions (such as Switzerland and the Netherlands), and most of the common law jurisdictions (including the United States and the United Kingdom), do not recognize the droit de suite, even though they may recognize other "moral rights" of artists. ${ }^{2}$ Common law jurisdictions, including particularly England and the United States, also generally do not recognize the droit de suite. ${ }^{3}$

In most jurisdictions that have adopted the droit de suite, exercise of the right is not optional but rather mandatory. More precisely, the right has generally been made both unwaivable (that is, the artist cannot sell works that are free of the obligation to pay a resale royalty) and nonassignable (that is, the right to collect resale royalties in a given work cannot be transferred by the artist to another person). ${ }^{4}$ These features of the right, which are conceptually distinct and as a practical matter need not be linked, are sometimes rather loosely characterized together as "inalienability."

Just as the form of the right varies across jurisdictions, so does enforcement. While artists in France receive substantial funds through the droit de suite, in ltaly the right appears to go largely unenforced, as it does in California.

1. For a survey, see de Pierredon-Fawcett (1991).

2. On moral rights, see Hansmann \& Santilli (1997).

3. In 1976, however, the state of California adopted the droit de suite by statute, giving visual artists a right to collect $5 \%$ of the gross sale price received in any resale of their work in which the price exceeds $\$ 1000$.

4. In California, however, the right is expressly made unwaivable but assignable. 
Academic commentary on resale royalty rights for visual artists - and particularly commentary by economists - has often been unfavorable. Nevertheless, those rights remain politically popular. Serious consideration was given to enacting a nationwide resale royalty right in the U.S. when, in 1990, the Visual Artists' Rights Act was adopted (see U.S. Copyright Office, 1992), and the European Union has recently entertained serious proposals to adopt a mandatory resale royalty right that would be uniform throughout the EU. ${ }^{5}$

Some of the basic issues raised by artists' resale royalties have been well surveyed in the existing literature. ${ }^{6}$ In this essay, we probe a bit more deeply the affirmative arguments that can be made for the right. We also compare the rationale for visual artists' resale royalties with the rationale for the now-well-established systems of royalty rights for authors and composers. This comparison is particularly useful both because some of the principal arguments made against artists' resale royalties also apply to copyright, and because the economic rationale for compensating authors with royalties has itself not been well explored. We also offer a few words about the related subject of display rights for visual artists. We conclude with some general implications for policy.

\section{THE NEED FOR LEGISLATION}

The droit de suite is a continuing property right that an artist maintains in his work regardless of who owns the (rest of the rights to the) work, and that is enforceable against the current owner of the work even if that person has never had any direct contractual dealings with the artist. In general, all legal systems make it extremely difficult - indeed, for all practical purposes, nearly impossible -- to create and enforce such rights unless the law makes explicit provision for them, as it already does nearly everywhere for copyrights and patents (see Hansmann \& Kraakman, 2000; Chafee,1928; Chafee, 1956). Consequently, in those jurisdictions that do not already recognize the droit de suite, specific enabling legislation must be adopted before an artist can retain a resale royalty right in work that he sells. Although, in jurisdictions lacking such legislation, there have been various efforts by individual artists to reserve resale royalty rights simply by contractual means, the practical enforceability of the rights thus created is questionable.

It follows that the questions of policy presented by resale royalties are twofold. The

5. Legislative Resolution embodying Parliament's opinion on the proposal for a European Parliamant and Council Directive on the resale right for the benefit of the author of an original work of art (COM(96)0097 - C4 - 0251/96 - 96/0085(COD)), Official Journal C 132, 28/04/1997 p. 88.

6. See, e.g., Filer (1984), Merryman (1997), and Perloff (1998) for thoughtful surveys of both the issues and the literature. 
first question is whether it is advisable to enact enabling legislation that simply permits, but does not require, that individual artists reserve a resale royalty work in some or all of their work, just as the law presently permits, but does not require, that authors retain copyrights and inventors retain patent rights. The second question is whether there are persuasive reasons to go even further and make resale royalty rights mandatory for all artists, in contrast to the approach taken for copyright and patent.

It also follows that the experience to date with the droit de suite, both in those countries that have adopted it and in those that have not, offers only limited guidance in approaching these questions of policy. In particular, the general absence of efforts to establish resale royalties in countries, such as the U.S. and the UK, where they are not explicitly recognized by law does not provide clear evidence that such rights are inefficient; in effect, the law in those countries now makes retention of a resale royalty right infeasible. At the same time, jurisdictions that recognize the droit de suite make it mandatory rather than optional, likewise ruling out a survivorship test of efficiency. Efforts to assess the efficiency of resale royalties must therefore depend largely on logic and analogies.

The law's generally unaccommodating attitude toward divided property rights of the sort involved in resale royalties, in which two or more persons both have ongoing rights in the same asset, has its roots in the complex administrative apparatus (involving, for example, public registries) and the elaborate sets of legal rules and presumptions that are necessary to make such rights workable. For example, with respect to resale royalties the law must provide some means by which the owner of a work of art can determine whether, to whom, in what amount, and how royalty payments must be made, and the law must likewise give artists some means for assuring that the requisite payments are in fact made.

For this reason, the wisdom of making legislative provision for resale royalties is closely tied to the available means for paying and enforcing the royalties. This is a complex subject that -- though of central importance in assessing the wisdom of a legislative droit de suite -- we will leave largely unexplored. Rather, we simply note that, for

the droit de suite to be advisable as a matter of policy, it must offer sufficient net benefits to outweigh the costs of the mechanisms, legal and otherwise, necessary to administer it.

\section{ARGUMENTS AGAINST RESALE ROYALTY RIGHTS}

In important respects, the droit de suite appears unattractive not just in terms of social efficiency, but more particularly from an artist's point of view, and especially from the viewpoint of the young artists for whom the right is likely to have most importance. The arguments to this effect, persuasively made elsewhere (see Filer, 1984, and Perloff, 1998; see also Karp and Perloff, 1993), can be summarized briefly. 


\section{A. Poor Lifetime Income Allocation}

To begin with, if an artist retains the droit de suite, then presumably initial purchasers of the artist's work will reduce the price they are willing to pay for the work by an amount roughly equal to the present discounted value of the expected future payments that the artist can claim. The result is that the artist gives up a certain payment in the present for risky future payments of roughly equal present value (less, of course, the administrative costs of collecting those payments). Since most artists presumably need income more when they are young and unestablished than they will later in their life, if and when they have become successful, this result seems undesirable as a matter of timing.

\section{B. "Negative" Insurance}

Resale royalty rights also appear undesirable as a matter of risk allocation. A young artist would seem to be a much worse risk bearer, so far as his future reputation is concerned, than are the galleries and collectors that purchase his work. Galleries and collectors are presumably richer and less liquidity constrained than young artists and, more importantly, can diversify the risk of any given work of art or any single artist by investing in the work of a number of artists.

Moreover, the gamble on future success embodied in the droit de suite is perverse from the artist's point of view, being a kind of reverse insurance that pays well if the artist is highly successful and nothing if he fails.

\section{Disincentives for Promotional Efforts}

Beyond these unfortunate income deferral and risk-bearing effects, the droit de suite's royalty claim can be expected to induce dealers, speculators, collectors, and other intermediaries to invest less effort in facilitating and promoting (re)sales of an artist's work than they would in the absence of that claim, since the royalties prevent them from capturing the full value of their efforts. The result should be to reduce overall demand for the artist's work, and hence the price at which the work will sell throughout its life.

\section{IV.POTENTIAL EFFICIENCY ADVANTAGES OF RESALE ROYALTIES}

If the preceding problems were the only foreseeable consequences of establishing 
resale royalty rights, there would be little reason to enact enabling legislation to permit artists to retain those rights, and no reason whatsoever to make those rights mandatory. There are, however, potential benefits of resale royalties that arguably could outweigh the disadvantages just described.

\section{A. Avoiding Ex Post Regret or Embarrassment}

Popular arguments for resale royalties often focus on stories about the plight of aging artists who, their work having achieved fame only after their productive years had ended, must see their families live in poverty while the work they sold cheaply in their youth commands a fortune at resale. If we are to try to make sense of such arguments from an economic point of view, it may help to expand a bit the conventional boundaries of economic analysis.

It is not obviously irrational for an artist to retain the droit de suite as a form of insurance against the possibility that his work will become famous while he remains poor, lacking the funds to live a life commensurate with his fame. One's sense of happiness is arguably tied not so much to one's absolute standard of living as to the relationship between that standard and one's expectations or image of what it should be or might have been. For this reason, it may be very painful to an artist to see his work selling for enormous amounts of money while he continues to live impecuniously -- painful enough to make it worthwhile to make (as it were) premium payments, in the form of lower sale prices for one's early work, to obtain insurance against this such an outcome.

Even viewed in its best light, however, an argument along these lines provides rather weak justification for resale royalties. In addition to the attenuated logic needed to support the argument, there is the fact that the great majority of artists whose work has ultimately become famous seem to have led fairly prosperous lives (see Filer, 1986). ${ }^{7}$ At most, such an argument might provide some support for an optional resale royalty right, not a mandatory one.

\section{B. Reputation Effects}

More compelling arguments for resale royalty rights derive from the types of

7. Moreover, to the extent that the droit de suite is intended simply as a means of giving an artist a speculative claim on future increases in the value of his work, developments in the modern art market have decreased the need for the right. Today, it is said, the period of time that transpires between an artist's early productions and the time that he establishes a solid reputation in the art market is much shorter than it was, say, a century ago. Also, the art market is, arguably, now sufficiently well developed that it evaluates with greater accuracy than in the past the likely future value of an artist's work (or, put differently, there is less disparity between the present and future value of an artist's work now than in the past). 
reputational concerns that, as we have suggested elsewhere, also provide the most convincing justification for recognizing artists' moral rights (Hansmann \& Santilli, 1997).

\section{Signaling the Artist's Faith and Commitment}

The ultimate value of an artist's early work depends importantly upon his subsequent work. More particularly, an important reason why the value of a young artist's work increases over time is that he subsequently produces a sufficiently large and impressive body of work to give him, and thus all of his work, a strong reputation. If Picasso had stopped painting at the end of his blue period, surely his works from that period would sell for far less than they do.

Predicting an artist's future reputation requires knowledge about his talents, ambitions, capacity for work, and skills at self-promotion. The artist himself may have better information about these personal characteristics than do the galleries and collectors with whom he deals. Young artists who believe that they are unusually likely to be successful might therefore rationally wish to take part of their compensation in the form of a royalty right, while their less sanguine colleagues could reasonably prefer to sell all the rights to their work for a fixed price.

Perhaps more importantly, an artist's willingness to take part of his compensation in the form of a right to future royalties may be a convincing way for the artist to signal to prospective purchasers the artist's knowledge that his work is worth investing in -- that is, that the artist has what it takes, and will do what is necessary, to become successful. 8 By thus permitting talented young artists to distinguish themselves from their less talented contemporaries, some important efficiencies may be realized: there may be greater incentives for talented individuals to undertake a career as an artist, and purchasers may find it easier to evaluate artists. There is, however, also the threat that inefficiency may result from signaling of this sort. In particular, both talented and untalented young artists may face an incentive to oversignal, incurring excessive risk and deferring too much of their income in an effort to convince art buyers that they have talent and ambition. ${ }^{9}$

8. It might be argued that artists, and particularly the most inspired artists, are not commercially minded or motivated and hence would not respond to such incentives. This seems not, however, to be the case. Picasso, for example, was apparently quite shrewd about managing his career and his reputation with an eye to financial returns.

9. For an example of potentially inefficient over-signaling in a related context, see Rea (1984). 


\section{Screening for Strong Talent}

Talented young artists who believe accurately that they are likely to achieve high success, but who also believe that they may be unable to convince dealers and collectors of that fact until well into their careers, may sometimes be discouraged from pursuing art as a career, and instead deploy their talents in some other field, because they fear that the absence of resale royalties will prevent them from capturing a sufficient share of the returns from their artistic efforts. And the reverse may be true of artists who accurately believe themselves to be on the low end of the talent distribution.

Thus, a second potential justification for the droit de suite is that, by redistributing (expected) income among artists in favor of the most successful artists, there will result not just the unfortunate risk-bearing and liquidity effects mentioned above, but at the same time a much stronger incentive for potentially strong artists to enter the profession and to persevere, and less incentive for the weaker artists to do the same. Greater productivity and a richer artistic patrimony - could be the result.

\section{Creating Reputational Incentives}

Beyond signaling to prospective purchasers the artist's ability and intention to build a strong reputation, an artist's retention of a resale royalty right gives the artist an incentive to build that reputation. Because improvements in an artist's reputation generate positive externalities, in the form of increased value for works that the artist has already sold, the private benefits to the artist from building his reputation are smaller than the total social benefits. If the artist retains a royalty right in his already-sold works, this problem is rectified to a degree, permitting the artist to benefit from the increase in value of his entire oeuvre that results from building his reputation. ${ }^{10}$

For similar reasons, resale royalties can be a supportive complement to artists'

\footnotetext{
10. The potential value of the droit de suite in addressing this externality problem is noted, at least briefly, by Filer (1984) and by Karp and Perloff (1993).

Solow (1998) also briefly notes this possibility, but focuses his analysis principally on the reverse namely, that the droit de suite might allow the artist to overcome the "durable goods monopoly" problem by reducing his incentive to produce a large number of later works whose presence on the market would decrease the value of his earlier work. This problem only arises if, in fact, the artist's later works are substitutes rather than complements for his earlier works. If that were the case, there would be good reason not to pass legislation establishing the droit de suite, since the effect would be a decrease in consumer welfare. There may be some artists -- particularly those whose most creative period occurred during their youth -- for whom later production reduces the value of earlier production; De Chirico and Dali' are arguably among them. For most artists, however, casual empiricism suggests that later production has, if anything, a positive effect on the value of the artist's early production.
} 
moral rights. A potential problem with moral rights doctrine is that the artist -- who is generally the only individual who has standing to enforce moral rights -- may lose any substantial material interest in the marketability of his oeuvre when he reaches the end of his productive career and has sold all or nearly all of his work (See Hansmann \& Santilli, 1997). The droit de suite mitigates this problem, giving the artist a continuing financial stake in the value of all of the work he has produced, and thus giving him as well an incentive to serve as a good fiduciary for the interests of the current owners of his works, and of the public at large, by continuing to police his moral rights.

\section{Other Solutions}

It has been argued that the droit de suite may be superfluous, since there are other means available to an artist to retain the possibility of profiting if he should subsequently become famous. First, he can produce more works after he becomes famous. Second, he can decline to sell some of his early work, keeping it to sell only if and when his reputation, and hence the market value of the work, has substantially increased.

Both of these strategies have serious liabilities, however. For some artists, it is the earlier work that is the basis of their fame; consequently, by the time their work commands high prices on the market, they can no longer produce pieces that will bring those prices. ${ }^{11}$ And, though keeping some of the early work unsold avoids this problem, that can be a difficult and costly strategy. First, it requires that the artist take a long position in his work, rather than just retain an option, and hence is costlier than retaining resale royalties.

Second, since the works held back can be sold only once, this strategy leaves the artist with the problem of determining when to sell. Third, since an artist's reputation is often enhanced by having his work sold and displayed, by holding onto his work an artist may lose, in terms of the value of his reputation, a portion of what he gains in the ability to profit from that reputation. Fourth, in contrast to resale royalties, this strategy does not permit the artist to retain a stake in a well-diversified sample of all of the work he produces. The droit de suite has the advantage that it gives the artist a continuing interest in the market value of the work done at each stage of his career, and does this without preventing the distribution of this work among the art-appreciating public.

\section{E. Weighing Costs and Benefits}

Having described some of the principal costs and benefits of compensating visual artists with royalties, the important question remains: do the benefits outweigh the costs?

11. De Chirico and Braque are prominent twentieth century examples. 
As we have noted, the existing legal regimes arguably leave us without a good test of this balance of costs and benefits. Important perspective on the potential for resale royalties can, however, be obtained by examining the experience with royalty payments for authors and composers, which exhibit many of the same costs and benefits. Before turning to that topic, however, it is helpful to see what can be learned from the fact that visual artists already use a royalty-type division of proceeds for the first sale of an artwork.

\section{ART DEALERS' COMMISSIONS}

Visual artists commonly sell their newly-produced works through art dealers on a commission basis in which the artist and the dealer each take a share of the ultimate sale price of each work. The obvious but rarely-used alternative is for the artist simply to sell his work to a gallery or other broker, which can then resell the work to the public on its own.

The near ubiquity of the commission arrangement suggests that this form of compensation is efficient (or at least that it maximizes an artist's net proceeds from initial sales of her work). One might therefore infer that a similar system of compensation, in which the artist receives a fraction of the proceeds from sales of her work, would be efficient for subsequent resales of artists' work as well, and would in fact be chosen by the parties involved, in those jurisdictions where it is not already mandated, if only the law were more accommodating. Upon examination, however, the most obvious reasons for using commission contracts for the initial sale of artworks do not carry over to subsequent resales.

A visual artist, and particularly a young artist, will commonly enter into an agreement with an art dealer under which the dealer is given the exclusive right to act as sales agent for the artist, including the right to act as broker not just for works that the artist has already completed but also for all works that the artist will produce over some period of years in the future. The apparent reason for this arrangement is that the dealer's efforts to promote the artist's work are likely to raise the market value of all of the artist's work -- that is, to have the quality of a public good for the artist's work as a whole. Giving the dealer the right to act as broker for all of the artist's work therefore permits him to capture a greater share of the returns from his promotional efforts, and thus gives him a stronger incentive to promote the work.

Such an arrangement for exclusive representation might be combined with either of two methods for determining the division of sales proceeds between the artist and the dealer. The first is that which is commonly seen, in which the artist and the dealer each take a fraction of the ultimate purchase price received for each work sold. The second is one in which the dealer simply purchases the works from the artist outright and then resells them, keeping for himself any difference between the price the dealer pays the artist and 
the price received from sale to the public.

Why is the first method the one generally chosen? Given that the dealer is to be given the exclusive right to represent the artist, not just for already completed works but also for works to be created in the future, the second method creates undesirable incentives for both artist and dealer. If the price to be paid the artist by the dealer for future works is fixed in advance by the parties' contract, the artist has an incentive to skimp on effort and produce only works of low value. If, alternatively, the price is left to be negotiated by the parties for each individual work as it is produced, the dealer can use his position as exclusive agent to force monopsonistically low prices on the artist. Tying the artist's proceeds to the final sales price received by the dealer controls these perverse incentives for both artist and dealer, giving the artist an incentive to produce works of high quality while preventing the dealer from exploiting excessively his position as exclusive agent.

In short, given that an art dealer is to serve as sole sales agent for an artist not just for already-produced work but also for future work not yet produced, there is little alternative but for the artist and the dealer to agree in advance to divide between themselves, on some percentage basis, the gross proceeds from sale of each of the artist's works. This reasoning does not carry over directly to resales, however, since the collector reselling the work will typically have no ongoing arrangement to purchase further works from the author, the terms of which might need to be tied to the terms of resale. A collector who wishes to sell a painting may choose to (a) sell the painting directly to another collector, (b) sell the painting directly to a dealer, who will resell the painting for his own account, or (c) sell the painting with the help of a dealer or auction house, giving the dealer or auction house a share of the gross sale proceeds as an incentive. The original artist need not necessarily be involved in the terms of any of these arrangements.

Karp and Perloff (1993) offer a different reason for compensating art dealers on a commission basis, and assert that the same reason supports artists' resale royalties. They construct a model that assumes that the dealer is to be given exclusive rights to sell all work produced by the artist (the reason being that the dealer's promotional efforts have the quality of a public good for all of the artist's production. The model also assumes that the dealer must have sole discretion to set the price at which the artist's work is sold to the public. Karp and Perloff then compare, in the context of this model, two alternative arrangements between the dealer and the artist. In the first, the dealer simply purchases the artist's works for a fixed price and then keeps the entire proceeds from sale to the public. In the second, the artist is compensated with a share of the gross or net proceeds from the dealer's sale of the works. Karp and Perloff show that the artist and the dealer may prefer the second arrangement. The advantage of the second arrangement is that it can reduce the dealer's incentive to use its monopoly power (as the artists's exclusive representative) to charge an inefficiently high price that reduces the total quantity of the artist's work sold below the level that would maximize either the artist's income or the artist's and dealer's joint profits. 
Karp and Perloff do not offer explicit analysis of subsequent resales, but simply assert that the same analysis applies to resales, saying in a footnote: "We ignore the possibility that the art is resold by the collectors [who purchase from the initial dealer] because the effects of further royalties only reinforces the results illustrated by this simple model" (1993, p. 175, n. 10). But in fact the model does not appear to extend to resales. Dealers do not retain exclusive rights to act as intermediary in resales of all of an artist's work. Consequently, the incentives for monopoly pricing that are at the core of the model do not arise in resales. A collector who owns only one of an artist's paintings, and who wishes to sell it, does not face a tradeoff between the price he charges and the quantity he sells, and a dealer through which the collector sells generally will not face such a tradeoff either.

Thus, the model applies no further than commissions for dealers. And in that relationship, resale royalty rights are unnecessary to give the artist a claim on a share of the proceeds from the dealer's sales, which can be - and is - established through simple contracting between the artist and the dealer. Legislation authorizing royalties is needed only for resales, after the work has left the hands of both the artist and his dealer, since the artist does not contract directly with subsequent purchasers.

Karp and Perloff's model also seems unnecessary to explain the common practice of selling art through a commission contract between the artist and his dealer. As we suggest immediately above, commission contracts can be justified convincingly on the basis of other considerations. Karp and Perloff are perhaps acknowledging the dominance of those other considerations when they observe: "That pattern [of proceeds division predicted by the Karp and Perloff model] is close to what is commonly observed (though perhaps for other reasons)" (1993, p. 168; italics added).

\section{VI.COMPARISON WITH AUTHORS' AND COMPOSERS' ROYALTIES}

Supporters of the droit de suite sometimes argue that it does no more than give visual artists royalty rights analogous to those commonly retained by authors and composers. Opponents argue that the two have little connection: authors' and composers' royalties are associated with the reproduction of a work of art, while resale royalties are based on resales of the same object.

To make clear sense of the comparison, one must necessarily reflect on why it is that authors and composers are commonly compensated, in considerable part, through royalties rather than just with a lump sum payment for the sale of their copyright. Rather surprisingly, this is an issue that has received little thoughtful attention in the literature (but 
see Hansmann \& Kraakman, 1992). We shall therefore explore it here, focusing principally on authors for specificity.

Nominally, most authors of books are compensated entirely via royalties. While authors often receive a fixed payment from the publisher prior to publication of the book, that amount is generally in the form of an advance on future royalties, and is deductible from those royalties. Nevertheless, since it is common practice among publishers not to demand return of the advance if royalties are ultimately insufficient to cover it, the terms of payment for an author's work effectively take the form of a fixed payment plus a right to royalties if total sales exceed a given target. For most books, the advance constitutes most or all of the author's compensation. For the relatively small percentage of books that attract a large audience, however, royalties beyond the advance constitute a large fraction of the author's compensation.

\section{A. Arguments Against Royalties for Authors}

Using royalties to compensate authors, rather than having the publisher simply purchase the author's copyright for a fixed sum, is subject to the same basic objections, surveyed above, that have been offered against resale royalties for visual artists: (1) they shift authors' income from their young years, when they are most likely to be liquidity constrained, to their later years; (2) they place market risks on authors rather than their much better diversified publishers; and (3) they provide negative insurance, handsomely rewarding the most successful authors at the expense of the much larger number who never attract a large readership. Nonetheless, authors routinely contract to be compensated through royalties.

Evidently, in the case of authors, there are affirmative reasons for employing royalties that outweigh these contrary considerations. It therefore seems natural to ask what those affirmative reasons for authors' royalties are, and whether they extend as well to resale royalties for artists.

\section{B. Arguments Favoring Royalties for Authors}

There are a variety of efficiency arguments in favor of compensating authors with royalties rather than with fixed payments. All of these arguments also extend in some form to contracting for the works of artists. In the case of artists, however, these arguments sometimes support only a commission arrangement for the first sale of an artist's work, and not a royalty on subsequent resales. 


\section{Reputational Externalities}

Royalties give authors a continuing incentive to promote their work after selling the manuscript, both directly by going on book tours and indirectly by writing other successful books and generally promoting their reputation as an author. This of course parallels the analogous logic discussed above in support of the droit de suite. ${ }^{12}$

\section{The Author's Informational Advantage}

An author, like an artist, may sometimes know more than does a prospective publisher about the likely success of the author's work. Perhaps more importantly, an author, like an artist, is likely to know better than a publisher just how committed the author is to writing other books in the future, and to promoting his career in general. Given that subsequent books, like subsequent art works, are often important in determining the ultimate success of early works, this is important information. By taking payment in the form of royalties, an author can signal to a publisher her confidence in the book at hand and in her future work, and can also reduce the risk for the publisher that the quality of the book and the author are not what they seem.

Beyond signaling, royalties for authors can also help screen - at the time individuals decide whether to try out a career as an author -- in favor of authors who know themselves to be unusually talented.

As we have noted above, these asymmetric information arguments, as applied to artists, can support an artist's claim to a fraction of the sale price of his works, not just for the first sale of the artist's work to the public through a dealer or gallery, but also to subsequent resales. The same is not true of the next argument we consider, involving the reverse form of asymmetric information.

\section{The Publisher's Informational Advantage}

Whether or not authors often have important information that publishers lack, it is likely that publishers often have information that authors lack - for example, concerning a

12. The law of many countries, and since 1976 the law in the United States as well, has prevented authors from giving up the copyright to their work for more than a specified number of years. In the United States, for example, the copyright in a work must revert to the author of the work after 35 years. This restriction, which is generally unwaivable by the author, acts to some extent like the droit de suite, in the sense that it assures that the author (or his heirs) will profit if his work becomes highly successful long after it is first published. Presumably those jurisdictions that have enacted such a provision have done so in the paternalistic belief that simply creating the ability to contract for royalties is insufficient as a means of permitting authors to benefit from their subsequent success. 
book's marketability, and concerning the costs of publishing and marketing a book.

Compensating the author with royalties limits the publisher's ability to exploit that informational advantage when negotiating with the author over the amounts to be paid the author. Or at least this is true when, as is the general practice, the royalty rate is effectively fixed by trade usage, so that the publisher cannot exploit its informational advantage when negotiating for the royalty rate. Rather, the publisher must simply decide for itself whether the book is worth publishing given the customary royalty rate. Constraining the available contracts between publishers and authors in this way may lead to more efficient contracting for books overall. Or, to put it the other way, the problem of publishers' informational advantage may help explain why common commercial practice is apparently for publishers and authors to limit their contracts to royalty arrangements with a royalty rate fixed by usage.

Similar considerations arguably provide another reason, beyond those suggested earlier, why painters generally do not sell their paintings outright to galleries, but rather share, via a standard commission rate, in the price that the gallery obtains when selling the work to a collector. This argument does not, however, necessarily have application beyond the gallery's first sale of the work; that is, it does not necessarily support giving an artist a royalty on subsequent resales of her work. The gallery's informational advantage is presumably exhausted after the first sale of the work; it only involves special information that the gallery might have as to what that first sale price might be (a price that should impound the prospects for future resales of the work).

An important difference between books and paintings in this regard is that there is no meaningful resale market for most books. Rather, if there is high demand for a book, the publisher will meet that demand by printing more books rather than, as with works of visual art, by selling each individual printed book at a higher price. To mitigate the publisher's informational advantage, the author must be given a fraction of the price at which each book is sold. Copyright does not give an author the right to collect a royalty on subsequent resales of individual books, just as, in jurisdictions that have not adopted the droit de suite, artists cannot effectively retain resale royalty rights. This is a matter of irrelevance for most authors, since, as just remarked, there is generally no substantial resale market for books. But if there were, the information asymmetry argument would not require that authors be given a resale royalty, any more than it requires that artists be given such a right.

It is interesting to note, in this connection, that if authors' agents played the same role in marketing books that galleries play for painters, then the information asymmetry argument might not require that authors receive royalties at all. Suppose, for example, that authors were typically to enter into a contract with an agent whereby the agent auctions the copyright to the book to publishers, selling the rights to the highest-bidding publisher and dividing up the price received between the author and agent so that each takes a 
percentage. Then, if the auction were sufficiently competitive, the sale to a publisher could be made for a lump sum payment, with no subsequent royalty payments to be made to the author, without concern that the publisher would be able to exploit unduly the author's informational disadvantage. The reason is that the bidding competition would eliminate the publishers' ability to exploit their informational advantage vis-àvis the author; they would be forced to reveal (something close to) their true estimate of the book's value.

Something like this bidding arrangement is, in fact, employed for the most prominent authors, who sometimes auction off the rights to a forthcoming book for extremely large advances. For less established authors, however, including many who use an agent, we do not see such auctions. An important reason for this is that publishers will typically evaluate a book for publication only if they are given, for the period of their review, the exclusive right to publish the book. This latter arrangement, in turn, evidently reflects the substantial effort that a publisher must put into evaluating a manuscript: If several publishers were to evaluate a manuscript simultaneously, the search costs for each might well exceed their expected gains. The result is that, even with an agent, most authors are effectively dealing with a monopsonist when they submit a manuscript to a publisher, putting the publisher in a good position to exploit its private information if a royalty arrangement is not employed.

If the original purchaser of the copyright to a book resells its rights to another publisher, the asymmetric information rationale for royalties seemingly ends. One might therefore expect that subsequent sales of rights between publishers might be for a lump sum, with that sum to be divided according to some pre-established ratio between the author and the first publisher -- as with paintings that are sold to collectors by the gallery that first displays them. Casual empiricism suggests, however, that authors commonly retain a royalty right even in works that are resold in this fashion. The explanation, perhaps, is that it would be hard to specify, at the time of the first deal between the author and the original publisher, some other workable arrangement for resale of the rights by the publisher. If the publisher is given the right to resell for a determinate sum subject to a fixed sharing with the author, the publisher would have an incentive to engage in such a resale whenever the success of the book to date makes it clear that the publisher's percentage of the resale proceeds exceeds his after-royalty profit from continuing to publish himself, and vice-versa. And if the publisher has no right to resell its rights without the author's consent, the author might use his veto power to increase his take from the book upon resale even when transfer to another publisher would make sense, as when another publisher can better market the book, or when the original publisher becomes insolvent.

\section{Incomplete Work}

A final reason for compensating authors with royalties is that the author's manuscript is not completed. Often a publisher purchases publication rights to a book while it is still in 
progress. In that case, tying the author's compensation to the profits from book sales is necessary to keep the author from shirking after signing the contract. Again, there is a parallel to paintings and other works of visual art. Although such works generally are not purchased before they are complete (though specific works sometimes, of course, are commissioned), as we noted above it is not uncommon for a painter to develop a relationship with a given art dealer or gallery, either formally or informally, under which the gallery has the exclusive right to deal in the artist's future work -- so that, when an artist first develops a relationship with a dealer, he is in effect selling the rights to work that has not yet been completed.

This consideration does not, however, apply either to books or to works of art that have already been completed. Consequently, for artists, it does not provide support for a resale royalty.

\section{An Overall Comparison}

The fourarguments, just surveyed, for compensating authors with royalties also strongly support the original sale of paintings and other works of visual art on a commission basis, rather than having the artist sell the works outright to a dealer. The overall support that those arguments provide for artists' resale royalties is less clear. The latter two of those four arguments arguably do not extend at all to resale royalties. On the other hand, the first argument surveyed here - based on reputational externalities - arguably provides stronger support for compensating artists than authors with a fraction of the proceeds from future sales of their work, including (in the case of artists) resales. That is because, in general (though by no means always), artists produce a much larger number of individual works than do authors, and the reputational externality across those works seemingly plays a larger role in the value of any individual work than is true for books.

\section{Metering}

Finally, there are distinctions between artworks and books in both the practicality and the necessity of using royalties as a means of assessing and collecting a share of the ultimate market value of creative work. These distinctions make the case for authors' royalties stronger than is the case for artists' resale royalties.

The problems of practicality are relatively familiar. Resales of an artists' works provide a measure of the market value of that work that is much cruder - and more easily evaded -than is the measure of a book's value that is provided by continuing sales of the books. Resale royalties are payable only when there is a market sale of the work. But such resales are highly stochastic events: They may occur often or only at great intervals, depending on circumstances that often have little to do with the value of the work. There 
are also problems of the scope of application, as in determining whether donation of an artwork to an individual or to a museum should be considered a sale for purposes of paying resale royalties, and if so how the imputed price is to be determined. And there are problems of evading resale royalties by conducting sales of artworks in jurisdictions that do not enforce the payment of those royalties.

Second, consider necessity. The marketable output of authors is commonly much more "lumpy" than is the work of artists. Painters, for example, usually produce a large number of works over time, while even successful authors may produce only one or a few works of any substantial popularity. Consequently, a painter is commonly in a good position to profit from the success of early works by producing and selling more works later on, while the same opportunity is far less available to an author. An author who wants to make sure that she will gain from any success that an individual book may meet often has little choice but to take compensation through royalties for that particular book.

\section{DISPLAY RIGHTS}

In many jurisdictions, the copyright granted to the author of a dramatic work, or to the composer of a musical composition, extends to individual performances of the work.13 Consequently, the author can insist on royalties for each performance. It has sometimes been argued that an analogous "display right" should be included in the copyright granted to painters, sculptors, and other visual artists, permitting those artists to reserve to themselves the right to display a work of art publicly even after selling possession of the physical object itself (Santagata, 1995; Note, 1991; Goetzl \& Sutton, 1984). Under such a display rights regime, a painter could, for example, sell one of her paintings subject to the condition that, if it is ever displayed by a museum, she must be paid royalties measured by some index of the total viewership that the painting receives. There would be obvious complexities in designing an appropriate index for this purpose, and in undertaking the accounting and policing necessary to assure payment of the royalties that the index calls for. These complexities would not, however, necessarily be more daunting than those involved in the long-established systems of accounting for royalties for music performances and broadcasts.

The issues raised by display rights are in some ways similar to, and in some ways quite different from, those raised by resale royalties. In further pursuit of the similarities and differences between contracting for works of art and contracting for works of authorship, we survey those issues briefly.

13 For a thoughtful economic and institutional analysis, see Towse (1999). 
Like resale royalties, display rights must be specifically authorized by legislation if they are to be practicably enforceable. Display rights could, however, be created with or without establishing a legal regime for resale royalties: As with performance rights for musical compositions, display rights could simply be granted by broadening the scope of the copyright that the law already permits visual artists to reserve for reproduction of their work.

The superficially appealing analogy to royalties for performances of plays and musical compositions does not, in fact, provide much support for such display rights. In the case of plays and musical compositions, performance royalties serve to permit price discrimination that, in turn, allows the author to capture a substantial fraction of the value of her work while permitting the efficient marketing of that work. With a right to performance royalties, for example, phonograph recordings or disks can in effect be sold to different types of users at different prices. The disks themselves can be sold at a price close to the cost of production, thus permitting widespread sale to individuals for noncommerical household use. Commercial users such as broadcasters can also purchase the disks at that price, but must then pay an additional amount in the form of royalties that reflects the value to them of playing the disks. Absent the ability to charge performance royalties, the disks would have to be either priced high enough to capture the value to substantial commercial users, thus foregoing the ability to sell to the home market, or priced low enough for the home market, thus foregoing the ability to capture most of their value to commercial users.

The situation is different, however, with paintings or sculptures for which only the original has substantial display value. Price discrimination is not an issue with such works: There is only one (important) copy of the work to sell, and it can be sold only at a single price. The price it brings, moreover, will reflect its value to the highest valuing user. Thus, if a painting is put up for auction and the high bidder is a museum that values the work principally because it will attract a large number of viewers, then the price at which the painting is sold to the museum will capture some fraction of the value to those viewers of seeing the painting -- or at least some fraction of what the museum is able to extract from those viewers, directly and indirectly (e.g., through private donations and public grants), for the ability to see the painting, which is all that a display royalty could capture in any case. There is no question of being able to sell the painting simultaneously to other, smaller museums, or to private collectors, at a lower price, thus also capturing the value to them of the painting, since the painting, unlike a musical recording, cannot be sold to more than one purchaser at the same time.

There is, however, a stronger rationale for display royalties that is based on reputational interests. A painter who has already sold a substantial number of paintings can increase the value of those paintings to their current owners by actions he takes to enhance his general reputation -- such as by painting more and better paintings. Under present law, however, he cannot capture any of that increase in value to his already sold 
work, and hence he has insufficient incentives to continue to advance his career as an artist. Display royalties could help solve this problem, permitting the artist to internalize more of the benefits from his work.

In short, reputational phenomena provide some justification for extending visual artists' copyright to include full display rights, and artists might be able to use such display rights, in turn, to control the presentation of their work to the public in ways that would enhance their overall reputation, for the benefit of both themselves and all other owners of their work. The underlying policy problem, therefore, is whether this reputational argument is sufficiently strong to justify the formidable difficulties of administering a regime of display rights, particularly given that such a regime, even if reasonably well implemented, might be at best a very imperfect meter of the value of individual works.

\section{SHOULD ROYALTIES BE UNWAIVABLE?}

Even if the potential justifications for artists' resale royalties that we have surveyed seem sufficient to counsel adoption of legislation that would make such royalties enforceable, those justifications do not necessarily require that the right be unwaivable. In fact, at least one of those justifications actually requires that the right be waivable - namely, the argument that through her willingness to accept the droit de suite (i.e., to take part of her compensation for a work in the form of a claim on future appreciation in its value) an artist can credibly demonstrate to prospective purchasers of her work her faith in its quality and her commitment to work in the future to increase her reputation. As we have noted, however, all jurisdictions that have adopted the droit de suite have apparently made that right unwaivable, in conspicuous contrast to copyright. It remains to inquire, therefore, what the arguments for unwaivability might be.

Paternalism toward artists, who might be persuaded too easily to waive their royalty rights, is one conventional justification for making retention of the right mandatory for artists. It is difficult to see why the paternalism argument is stronger for artists than it is for authors or composers, for whom royalty rights are generally waivable. There are some

other considerations, however, that could arguably support a mandatory (unwaivable) right. 


\section{A. Reinforcing the Artist's Role as Fiduciary for His Work}

If the objective of the droit de suite is to assure that the artist has a continuing interest in his oeuvre as a whole, then there exists a bonding argument for making the right unwaivable. A purchaser of one of the artist's works will have more faith that the artist is committed to working to maintain or enhance the value of that work, by continuing to develop his reputation as an artist, if the artist not only retains a financial interest in the particular work in question but also in all of his other work, including any works that the artist sells in the future. But an artist could not easily bind himself, in the contract of sale for the work in question, not to waive the droit de suite for his other works. A legal rule of unwaivability makes his commitment secure.

\section{B. Scale effects}

If legislation were enacted to enable artists to retain the droit de suite, but the right were made waivable, there might be a risk that the right would be waived by nearly all artists because of scale effects.

For the resale royalty right to be effective, purchasers of artworks must be made aware of the existence and nature of the right, and a recording system must be established for maintaining records of the ownership and sales of each of the artworks covered by the right. Even if the government were to bear some of these costs - e.g., by setting up a publicly-maintained recording system - some of these costs would be borne by artists, dealers, and patrons.

If, initially, only a few artists were to retain the right, while all others waived it, the transaction costs facing those artists, and their dealers and prospective patrons, might be so high as to negate any advantages that could come from retention of the right. If, on the other hand, most or all artists were to retain the droit de suite, then the transaction costs involved in enforcing the right would presumably be modest on a per-artwork basis. Consequently, artists as a group, and perhaps art dealers and purchasers as well, might have an interest in entering into a mutual agreement that all artists will retain the droit de suite. But such an agreement is difficult to undertake effectively by private means. It follows that, if the droit de suite appears efficient as a general practice, there is an argument for having the government make the right unwaivable, and hence force artists and purchasers of art to share broadly among themselves the initial transactions costs necessary to make the right effective.

Inalienability can often best be justified on the grounds that the interests of third parties are involved -- that is, that third parties would suffer from alienation of the right. The argument just offered is of this character: If any individual artist waives the droit de suite, 
this increases the per capita transaction costs that other artists must incur when they exercise the right.

To be sure, if this is the principal justification for unwaivability, then unwaivability may be important, if at all, only in the years immediately following the initial recognition of the droit de suite. After that, the costs of notice and record-keeping might be expected to fall to the point where waivability is unlikely to lead to collapse of the droit de suite in general.

\section{Demonstration effects}

A related but slightly different justification for unwaivability is that, even if it is efficient for artists to retain the right, participants in the art market in general will fail to believe that fact until it has been conclusively demonstrated. If the right is made waivable, it will routinely be waived in the mistaken belief that it is not worth exercising. Only if the right is made unwaivable will it be exercised. Then, after it has been routinely exercised for a number of years, it will become obvious to participants in the art market that it is efficient, after which it will routinely be exercised whether it continues to be unwaivable or not.

A clear example of such demonstration effects can be found in home mortgages. Prior to 1935, home mortgages of greater than seven years' duration were effectively unavailable in the United States, because the conventional wisdom among lending institutions believed that a longer term would be too risky to permit a profitable loan at any acceptable interest rate. Then, in 1935, the federal government offered mortgage insurance at a price of $1 \%$ of the value of the mortgage, but only for mortgages of at least 20 years' duration. Banks and homeowners took advantage of the program, since consumers felt that a $1 \%$ increase in cost was a modest price to pay for tripling the term of a mortgage, while banks of course bore no additional risk. Experience with these loans subsequently demonstrated that default rates on the longer-term mortgages were far lower than had been expected. In fact, the government made a profit on its insurance program, and banks ultimately began to offer the longer-term mortgages themselves, without the government insurance, for a premium less than the $1 \%$ that the government was charging.

On the other hand, an objection to making the droit de suite unwaivable as a step toward demonstrating (or disproving) its efficiency is that, in contrast to the case of twentyyear home mortgages, the efficiency or inefficiency of the droit de suite will never be clearly demonstrated. It is easy to determine whether there has been a substantial default rate on a pool of twenty-year mortgages. But how will dealers and artists ever come to know whether the regime with the droit de suite is more efficient than the market was without it? To be sure, if the droit de suite is highly inefficient, in the sense that transaction costs of administering the right are clearly outrageously high or the market for paintings by young artists collapses in major part, then the fact will be transparently clear. But any less 
dramatic consequence is likely to be hard to measure.

There is also the objection that various European nations have long mandated the droit de suite, yet the result has not been to provide a clear demonstration of the efficiency of the right. Still, the European experiments may not be fully determinative: the royalty rates they involve may well be too low, for example, and the methods for notice and registration and enforcement that they have established may be insufficiently effective.

\section{Summary}

It is not obvious that the arguments that we have surveyed here are sufficient to make a convincing case for the unwaivability of the droit de suite, even if there is justification for enabling legislation authorizing the right. Those arguments do demonstrate, however, that there are substantial reasons for unwaivability that go well beyond the conventional paternalistic ones, and that some of the more persuasive arguments in favor of the droit de suite -- in particular, the argument that it reinforces the artist's incentive to consider the effects of his actions on his oeuvre as a whole, including those works that he has already sold -- also provide some justification for making that right unwaivable.

\section{CONCLUSION: A VOLUNTARY BUT STRONGLY ENFORCEABLE RESALE ROYALTY RIGHT?}

The arguments surveyed here do not obviously support strong conclusions about the efficiency of artists' resale royalty rights. Policy must, nevertheless, be made. We conclude with a few general thoughts on the issue.

Among those nations that have adopted the droit de suite, the right is generally mandatory, with a legislatively determined royalty right. At the same time, the right is often relatively easy to avoid, either because within-jurisdiction enforcement is weak or because it is easy to avoid the right by taking artworks to - or producing them in - a jurisdiction that does not recognize the right. Given the state of our knowledge, this pattern seems difficult to justify.

It would arguably make better policy to follow the pattern adopted for copyrights and patents, making the right nonmandatory but easily enforceable both at home and abroad. More specifically, artists could be permitted to retain a resale royalty right, but the right could be made optional (waivable), and the royalty rate could be left to be set by the selling artist. At the same time, international treaties could be pursued to assure that resale royalty rights created in one country are enforceable in other countries could be reinforced 
by treaty, as well, including countries that do not themselves provide for creation of artists' resale royalties.

The market - artists, dealers, and patrons - could then be left to determine whether resale royalties are efficient. The alternative approach currently being promoted in the European Union - a mandatory EU-wide resale royalty right - may, conversely, offer no convincing market test of the efficiency of the right, while encouraging highly inefficient efforts at evading it. 


\section{REFERENCES}

Chafee, Z. (1928) "Equitable Servitudes on Chattels". Harvard Law Review41: 945-1013.

Chafee, Z. (1956) "The Music Goes Round and Round: Equitable Servitudes and Chattels". Harvard Law Review69: 1250-64.

de Pierredon-Fawcett, L. (1991) The Droit de Suite in Literary and Artistic Property: A Comparative Law Study.

Filer, R. (1984) "A Theoretical Analysis of the Economic Impact of Artists' Resale Royalties Legislation". Journal of Cultural Economics 8: 1-28.

Filer, R. (1986) "The 'Starving Artist' - Myth or Reality? Earnings of Artists in the United States". Journal of Political Economy 94: 56-75.

Goetzl, T. and Sutton, S. (1984) "Copyright and the Visual Artist's Display Right: A New Doctrinal Analysis". Columbia Journal of Art \& Law. 9: 15-56.

Hansmann, H. and Kraakman, R. (1992) "Hands-Tying Contracts: Book Publishing, Venture Capital Financing, and Secured Debt". Journal of Law, Economics, and Organization 8: 628-636.

Hansmann, H. and Santilli, M. (1997) 'Authors' and Artists' Moral Rights: A Comparative Legal and Economic Analysis". Journal of Legal Studies 26: 95-144.

Hansmann, H. and Kraakman, R. (2000) "The Structure of Property Rights." Working Paper, Yale Law School.

Karp, L. and Perloff, J. (1993) "Legal Requirements that Artists Receive Resale Royalties". International Review of Law and Economics 13: 163-177.

Merryman, J. (1997) "The Proposed Generalisation of the Droit de Suite in the European Communities." Intellectual Property Quarterly 1: 16-36.

Note. (1991) "Copyright Royalties for Visual Artists: A Display-Based Alternative to the Droit de suite". Cornell L. R. 76: 510-548.

Perloff, J. (1998) "Droit de Suite". The New Palgrave Dictionary of Economics and the Law(Peter Newman, ed.). 
Rea, S. (1984) "Arm-Breaking, Consumer Credit and Personal Bankruptcy". Economic Inquiry 22: 188.

Santagata, W. (1995) "Institutional Anomalies in the Contemporary Art Market." Journal of Cultural Economics 19: 187-197.

Solow, J. (1998) "An Economic Analysis of the Droit de Suite". Journal of Cultural Economics 22: 209-226.

Towse, R. (1999) 'Copyright and Economic Incentives: An Application to Performers' Rights in the Music Industry". Kyklos 52: 369-390.

U.S. Copyright Office. (1992) "Droit de suite: The Artist's Resale Royalty, Copyright Office Report Executive Summary”. Columbia-VLA Journal of Law \& The Arts 16: 381-394. 